\title{
Chemical Composition and Crystal Structure of Oxide Inclusions Promoting Acicular Ferrite Transformation in Low Alloy Submerged Arc Weld Metal*
}

\author{
By Yukihiko HORII***, Kazutoshi ICHIKAWA**, Shigeru OHKITA**, Shuichi FUNAKI** \\ and Nobutaka YURIOKA**
}

\begin{abstract}
High toughness are requested in the weld metals for offshore steel structures and steel line-pipes used at low ambient temperatures. Micro-alloying of titanium and boron effectively improves the toughness of low-alloyed weld metals with tensile strength ranging between 490 and $590 \mathrm{~N} / \mathrm{mm}^{2}$. It is well known that refined intragranular ferrite or acicular ferrite nucleates on titanium containing oxides. However, there have been few reports on the chemical composition at local positions of these effective inclusions and their crystal structures.

Two types of submerged arc weld metals were used; one is a silicon-and-manganese type weld metal with a ferrite with aligned second phase and the other is a titanium type one with the acicular ferrite. The mechanical and metallurgical examination included the microscopic observation, Charpy impact tests of the welds and the characterization of oxides in weld metals with $X$-ray diffractions and analytical electron microscope.

The following facts were clarified from the above investigations. The oxides in the titanium bearing weld metal are crystallized in a form of $(\mathrm{Mn}, \mathrm{Ti})(\mathrm{Al}, \mathrm{Ti})_{2} \mathrm{O}_{4}$ with angularly rugged surfaces, while the oxides of a Si-Mn type are amorphous with smooth spherical shape. Titanium as low as $0.005 \mathrm{wt} \%$ in a weld metal satisfactorily crystallized oxides if titanium is included in oxides with aluminum and manganese.
\end{abstract}

Key Words: Submerged arc welding, Weld metal, Oxide, Acicular ferrite, Titanium, Boron, Silicon, Manganese, Transmission electron microscope, $X$-ray diffraction

\section{Introduction}

Sufficiently high toughness is requested in the weld metals of such steel structures as high pressure pipelines and offshore oil-and-gas production platforms served at low temperatures ${ }^{1)}$. Many researchers have earnestly studied the mechanisms of toughness improvement of the weld metals. It is widely recognized that good weld metal toughness is obtained by maximizing the amount of acicular ferrite (AF) with reducing the amount of grain boundary ferrite and ferrite with aligned second phase (FS) in an as welded region ${ }^{2-6)}$. This fact has driven extensive studies on the transformation mechanism and properties of acicular ferrite. Acicular ferrite nucleating at non-metallic substrates ${ }^{2,4-8,10-14)}$ have large angle boundaries each other ${ }^{11)}$, and ferrite with aligned second phase has laths with almost parallel boundaries $^{11}$. The fracture facet size of the former is smaller than that of the latter. Therefore, weld metals containing acicular ferrites show high toughness ${ }^{11}$. The addition of titanium and boron into a weld metal effectively realizes the acicular ferrite microstructure in highstrength low-alloyed steel weld metals with the tensile strength between 490 and $590 \mathrm{~N} / \mathrm{mm}^{2}$ for a wide heat input range ${ }^{4)}$. In fact, $\mathrm{Ti}-\mathrm{B}$ bearing welding materials are widely used for low temperature services ${ }^{4,7,8,11,16)}$. It is thus well known that boron segregates along austenite grain boundaries to suppress the austenite-to-ferrite transformation from the austenite grain boundaries, and that fine intragranular ferrite or acicular ferrite is nucleated on titanium containing inclusions ${ }^{4}$. Several kinds of inclusions have been suggested as a ferrite nucleation site in the titanium bearing weld metal. They are $\mathrm{TiO}^{4)}$, $\mathrm{Ti}$

\footnotetext{
* Received : 31 August 1994.

** Member, Nippon Steel Corporation

*** Member, Nippon Steel Corporation (Present address, Japan Power Electric Engineering and Inspection Co.)
} 
-oxides ${ }^{7,8)}$, and $\mathrm{TiN}^{9)}$. However, no general explanation for the necessary features as the ferrite nucleation site have been authorized. The formation of acicular ferrite in $\mathrm{Ti}^{8)}$ and $\mathrm{Ti}^{-} \mathrm{B}^{\mathrm{16})}$ bearing weld metals was affected by aluminum content, and the acicular ferrite formation was reported even for welds with less than $0.005 \mathrm{wt} \%$ titanium content ${ }^{14,15)}$. Therefore, the role of titanium in the acicular ferrite formation and the compositions of non-metallic inclusions should be reconfirmed. There have been few reports which clarified the chemical compositions at local positions of these inclusions and their crystal structures $^{5,6,14)}$. Full understanding has not been completed concerning the required conditions for the ferrite nucleation capability of inclusions in weld metals. Important questions remaining are why the oxides in silicon-manganese ( $\mathrm{Si}-\mathrm{Mn}$ ) type weld metals do not act as a ferrite nucleation site in spite of the existence of high volume fractions of oxides and why titanium is essential in the oxides capable of ferrite nucleation.

The present study characterizes oxides in weld metals made by submerged arc welding (SAW) and clarifies the essential characteristics of the oxides for the ferrite nucleation.

\section{Experiment-Part One}

\subsection{Objective}

The objective of the experiment-part one is to confirm a difference between the characteristics of oxides in a titanium bearing weld metal with $\mathrm{AF}$ and a silicon-and-manganese deoxidized weld metal with FS. The role of boron is to suppress the formation of grain boundary ferrite, and the acicular ferrite transformation is less influenced by the boron. For simplicity, a titanium bearing weld metal ( $\mathrm{Ti}$ type weld metal) was used instead of a Ti-B bearing weld metal.

\subsection{Experimental Procedure}

Two types of steel plates of the $25 \mathrm{~mm}$ thick ness were used. One is a titanium-oxide treated low aluminum bearing steel ${ }^{22}$ (steel STA in Table 1) and the other is an aluminum killed JIS SM400B steel (steel STB in Table 1). The former was used to produce $T i$ type weld metals and the latter was used to produce conventional $\mathrm{Si}^{-}$

Table 1 Chemical compositions of the steels (wt \%).

\begin{tabular}{|c|cccccc|}
\hline Mark & C & Si & Mn & P & S & Ti \\
\hline STA & 0.06 & 0.20 & 1.38 & 0.007 & 0.002 & 0.015 \\
\hline STB & 0.17 & 0.14 & 0.67 & 0.02 & 0.01 & - \\
\hline
\end{tabular}

Table 2 Chemical compositions of the SAW electrode ( $w \mathrm{t} \%$ ).

\begin{tabular}{|c|ccccc|}
\hline Diameter & $C$ & Si & Mn & $P$ & $S$ \\
\hline $4.8(\mathrm{~mm})$ & 0.004 & 0.07 & 2.38 & 0.005 & 0.005 \\
\hline
\end{tabular}

Table 3 Chemical compositions of SAW fluxes.

\begin{tabular}{|c|c|c|c|c|c|c|c|}
\hline Mark & $\mathrm{SiO}_{2}$ & $\mathrm{TiO}_{2}$ & $\mathrm{Al}_{2} \mathrm{O}_{3}+\mathrm{MnO}$ & $\mathrm{ICOO}_{8}+\mathrm{MgO}$ & $\mathrm{CaF}_{2}$ & Metallic elements & Others \\
\hline $\mathrm{TIB}$ & 3 & 12 & 21 & 49 & 11 & 3 & 1 \\
\hline $\mathrm{SiMN}$ & 4 & - & 21 & 58 & 13 & 3 & 1 \\
\hline
\end{tabular}

Table 4 Welding conditions.

\begin{tabular}{|c|c|c|c|c|c|c|}
\hline & Electrode & $\begin{array}{c}\text { Current } \\
\text { (A) }\end{array}$ & $\begin{array}{c}\text { Voltage } \\
\text { (iv }\end{array}$ & $\begin{array}{c}\text { Wolding apeod } \\
(\mathrm{mm} / \mathrm{s})\end{array}$ & $\begin{array}{c}\text { Heat Input } \\
(\mathrm{kJ} / \mathrm{mm})\end{array}$ & $\begin{array}{l}\text { Groove shape } \\
\text { (Unit in } \mathrm{mm} \text { ) }\end{array}$ \\
\hline \multirow{2}{*}{$\begin{array}{l}\text { Backing pass } \\
\text { alde }\end{array}$} & Looding & 950 & 36 & \multirow{2}{*}{11.7} & \multirow{2}{*}{5.9} & \\
\hline & Tralling & 850 & 40 & & & \\
\hline \multirow{2}{*}{$\begin{array}{l}\text { Finlshing } \\
\text { pass slde }\end{array}$} & Leading & 1200 & 36 & \multirow{2}{*}{11.7} & \multirow{2}{*}{6.6} & \\
\hline & Tralling & 850 & 40 & & & \\
\hline
\end{tabular}

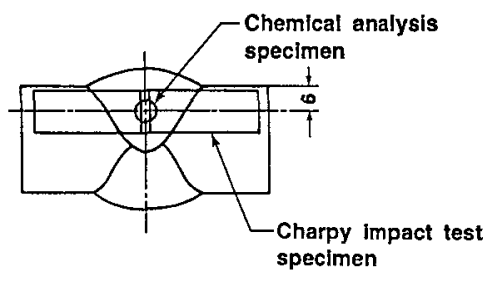

(Unit in mm)

Fig. 1 Location of test specimens.

Mn type weld metals. Table 1 shows their chemical compositions. This experiment employed SAW electrode wires from a laboratory-melt steel. The wire diameter was $4.8 \mathrm{~mm}$. Table 2 shows its chemical composition. Two types of agglomerated SAW fluxes were used (flux TIB in Table 3 for steel STA and flux SIMN for steel STB). Table 3 shows their chemical compositions. SAW with two electrodes in tandem was conducted using $\mathrm{X}$-groove preparation in an each-side one-pass manner. Table 4 shows this SAW conditions. The SA weld metals thus formed were subjected to Charpy impact tests and chemical analysis. Fig. 1 shows the location of the test specimens removed from a weld metal.

Microscopic observation was conducted on the specimens etched with $2 \%$ nital. Oxides in weld metals were characterized by a transmission electron microscope (TEM) observation. X-ray diffractions were carried out on the extracted residues of weld metals. Carbon extracted replicas were prepared to observe the oxides. For the replica preparation, the present experiment used nylon grids as specimen supports to prevent the extracted specimens from being contaminated by copper, instead of conventional copper grids. 
Analytical electron microscopy (AEM) was carried out using TEM operating at $400 \mathrm{kV}$ and 1000 $\mathrm{kV}$. Oxides for the $\mathrm{X}$-ray diffraction analysis were extracted in a bath of $10 \%$ iodine methanol solution with a magnetic stirrer.

\subsection{Experimental Results}

Table 5 shows the chemical compositions of the weld metals obtained in the present test. The content of titanium was acquired in an intended level ; it was $0.011 \mathrm{wt} \%$ in the Ti type weld metal and less than $0.002 \mathrm{wt} \%$ in the $\mathrm{Si}-\mathrm{Mn}$ type weld metal. Fig. 2 shows the microscopic structures of both weld metals together with $50 \%$ shear fracture appearance transition temperatures (FATTs) in the Charpy testing. It is seen that the Ti type weld metal consists of fine acicular ferrite and the $\mathrm{Si}-\mathrm{Mn}$ type weld metal mostly consists of FS. These microstructures reflect the results that the toughness of the Ti type weld metal is higher than the $\mathrm{Si}-\mathrm{Mn}$ type weld metal as indicated in their FATT values.

Table 5 Chemical compositions of the weld metals (wt\%, *: ppm).

\begin{tabular}{|c|cccccccccc|}
\hline Mark & C & SI & Mn & P & S & Al & TI & B $^{*}$ & $N^{\circ}$ & $0^{\circ}$ \\
\hline WMA & 0.04 & 0.17 & 1.62 & 0.006 & 0.003 & 0.009 & 0.011 & 2 & 26 & 269 \\
\hline WMB & 0.11 & 0.18 & 1.68 & 0.016 & 0.005 & 0.007 & $<0.002$ & $<1$ & 30 & 134 \\
\hline
\end{tabular}

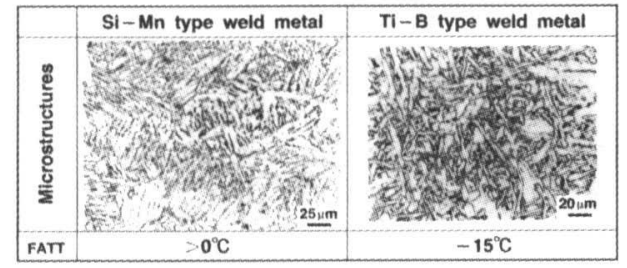

Fig. 2 Optical microstructures and FATT of Si -Mn and Ti type weld metals.

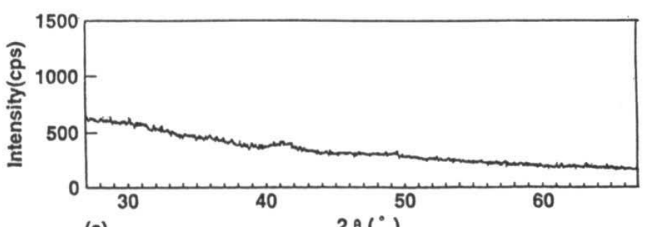

(a)

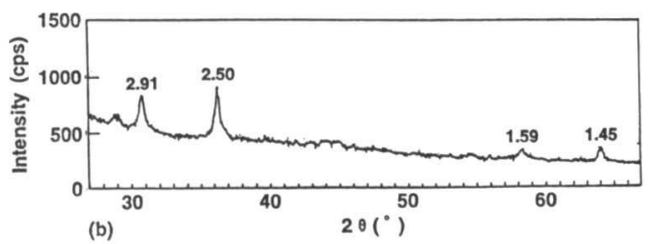

Fig. $3 \mathrm{X}$-ray diffraction results on the extracted residues of the weld metals. (a) $\mathrm{Si}-\mathrm{Mn}$ type weld metal, (b) Ti type weld metal. The numeral on the each intensity peak indicates its d value.
Fig. 3 shows the results of $\mathrm{X}$-ray diffractions on the extracted residues of the $\mathrm{Ti}$ and $\mathrm{Si}-\mathrm{Mn}$ type weld metals. No distinguishable intensity peak was shown in the result of the $\mathrm{Si}-\mathrm{Mn}$ type weld metal, while some peaks were identified in the Ti type weld metal although they were not intense. The spacing of lattice plane ( $d$-value) of these peaks satisfactorily matched with those of $\mathrm{MnAl}_{2}$ $\mathrm{O}_{4}$, a spinel type of structure according to the Powder Diffraction File Sets (PDFS) $29-880$ as shown in Table $6^{12}$. In addition, the lattice constant (a) of this oxide was 8.224 , also preferably matching with 8.204 of $\mathrm{MnAl}_{2} \mathrm{O}_{4}$ in Table 6. It is thus considered that the oxide in the Ti type weld metal has a spinel type of crystal structure same as $\mathrm{MnAl}_{2} \mathrm{O}_{4}$.

Ten oxides in the $\mathrm{Ti}$ and the $\mathrm{Si}-\mathrm{Mn}$ type weld metal respectively were subjected to not only the TEM observation by AEMs including bright field images and dark field images but also the energy dispersive spectroscopes (EDS). Fig. 4 shows an example of the TEM observations on the oxide of the Ti type weld metal. As shown in Fig. 4(a), the oxide was approximately $0.5 \mu \mathrm{m}$ in diametar, indicating angularly rugged surfaces. Fig. 4(b)

Table 6 Identification of oxides by X-ray diffractions.
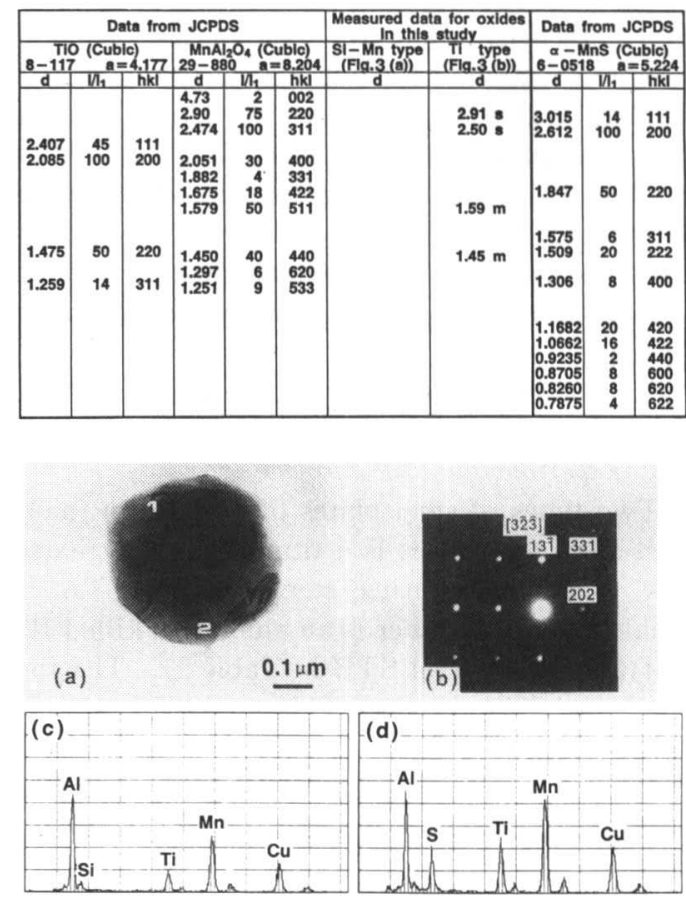

Fig. 4 Example of TEM observations on oxides in Ti type weld metal. (a) Bright field image, (b) Electron diffraction image of the oxide, (c) EDS analysis on point 1 in (a), (d) EDS analysis on point 2 in (a). 
shows an electron diffraction image of this oxide, identifying that its crystal structure is of a spinel type. This result of the diffraction image coincides with the identification of the extracted residues by X-ray diffractions. Miller indices of this crystal were identified as those shown in Fig. 4(b). Figs. 4(c) and 4(d) show the results of the EDS analysis at the points on the oxide as marked by 1 and 2 in Fig. 4(a), respectively.

The results of these observation indicate that the oxide consists fundamentally of aluminum, titanium, manganese, sulfur and copper. There was a spot observed at a point 2 in Fig. 4(a) which indicates high peaks of manganese and sulfur in EDS as shown in Fig. 4(d). This point was thus identified presumably as manganese sulfide. However, this manganese sulfide was too small to be observed by X-ray diffractions as shown in Table 6 . This observation suggests that oxides in the Ti type weld metal is not chemically uniform at least on their surface. The existence of TiN had been expected, but it was not detected in the electron diffractions.

Fig. 5 shows an example of the TEM observations on the Si-Mn type weld metal. The bright field image of Fig. 5(a) indicates that the oxide is approximately $0.5 \mu \mathrm{m}$ in diameter which does not differ from the size of oxides in the Ti type weld metal. However, the oxide in the $\mathrm{Si}-\mathrm{Mn}$ type weld metal exhibited a nearly spherical shape with a smooth surface. Figs. 5(b) and 5(c) show the EDS analysis results at the points of mark 1 and 2 in Fig. 5(a) respectively. The basic chemical composition of the oxide in the $\mathrm{Si}-\mathrm{Mn}$ type weld metal is aluminum, silicon, manganese, sulfur and copper, as shown in the EDS result of Fig. 5(c). The EDS intensity of silicon in the Si-Mn type is higher than that in the Ti type. The EDS intensity of Fig. 5(b) corresponding to spot 1 displays
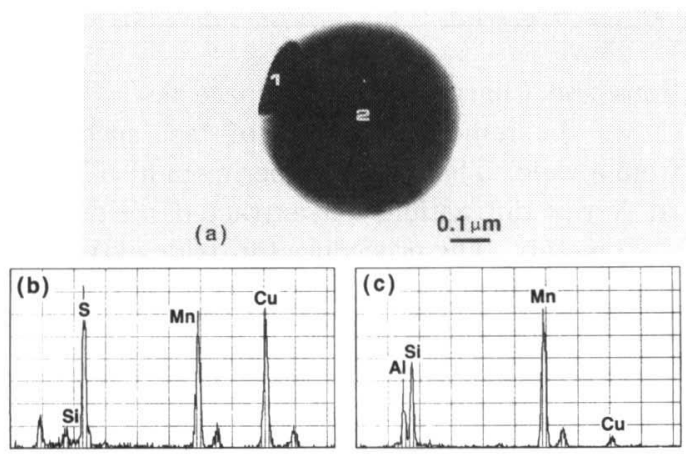

Fig. 5 Example of TEM observations on oxides in $\mathrm{Si}^{-\mathrm{Mn}}$ type weld metal. (a) Bright field image, (b) EDS analysis on point 1 in (a), (c) EDS analysis on point 2 in (a). the obviously high peaks of sulfur and copper. This implies that the deposition of (manganese and/or copper)-sulfide exists on the surface of oxides in the $\mathrm{Si}-\mathrm{Mn}$ type weld metal. The chemical composition was uniform at the surface of the oxide except a depositjon of the spot 1 .

Fig. 6 is another example of TEM image observations and electron diffractions by a $1000 \mathrm{kV}$ $\mathrm{AEM}$ on an oxide in the $\mathrm{Si}-\mathrm{Mn}$ type weld metal. Fig. 6(b) shows electron diffraction image of the oxide of Fig. 6(a), indicating a halo pattern which is typical for the diffractions of amorphous substances. However, Fig. 6(b) displays two distinct diffracted spots. To clarify the source of these spots, two dark field images were taken. Fig. 6(c) is one dark field image from the diffraction at the location which also shows a halo pattern as in dicated in Fig. 6(d). In this dark image, a base matrix of the oxide is slightly bright. Therefore, a matrix of the oxide corresponds to the halo pattern diffraction; that is, the matrix of oxides

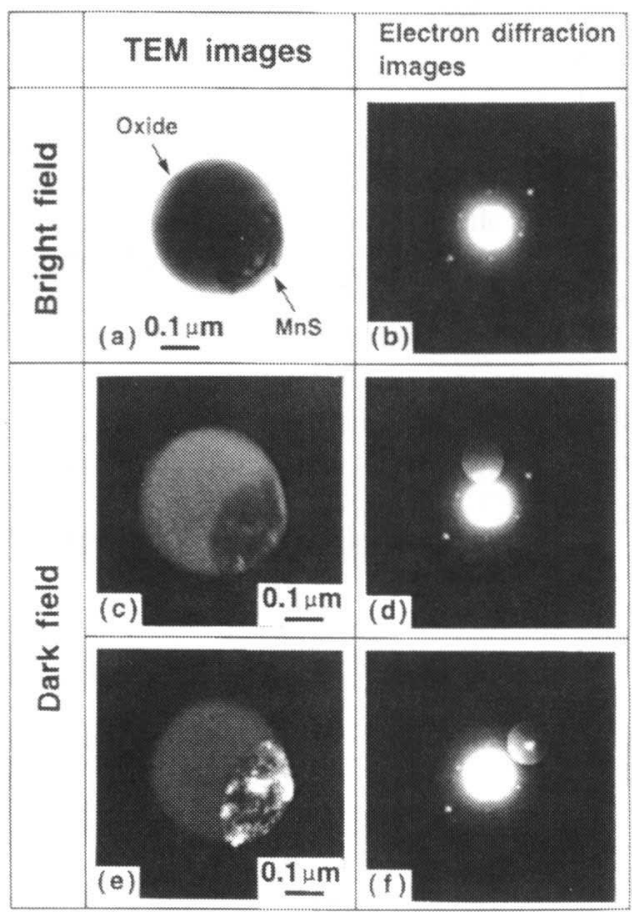

Fig. 6 Example of electron diffractions on oxides in $\mathrm{Si}-\mathrm{Mn}$ type weld metal. (a) Bright field image, (b) Electron diffraction image, (c) Dark field image from the halo pattern in the electron diffraction, (d) The location selected for dark field image observation (c) in the electron diffraction, (e) Dark field image from the diffracted spot in the electron diffraction, ( $f$ ) The location selected for dark field image observation (e) in the electron diffraction. 
in the Si-Mn type weld metal has an amorphous structure. Fig. 6(e) is another dark field image from the diffracted spot indicating a crystal struc. ture image, as shown in Fig. 6(f). A slightly bright portion in the dark field image of Fig. 6(e) corresponds to Fig. 6(f). This portion is a deposit of ( $\mathrm{Mn}$ and/or $\mathrm{Cu}$ )-sulfide like that shown in Fig. 5. It was, therefore, proved that the deposits on oxides are crystallized in the $\mathrm{Si}-\mathrm{Mn}$ type welds.

\section{Experiment-Part two}

\subsection{Objective}

The experiment-Part one revealed that the oxides in the Ti type weld metals have a spinel type of crystal structure while those in the Si-Mn type weld metals have an amorphous structure. The oxide in the Ti type welds identified in the experiment-Part one was neither TiO nor the other titanium dominant oxides. But it was identified as a spinel type oxide like $\mathrm{MnAl}_{2} \mathrm{O}_{4}$. Main chemical compositions of oxides in the $\mathrm{Ti}$ type and the Si-Mn type weld metal were silicon manganese and aluminum. The most significant difference between oxides in both type weld metals is a titanium content. Therefore, the authors considered that titanium in oxides plays a significant role in transforming an oxide structure from amorphous to crystal. In fact, titanium is used as a catalyzer for the crystallization of glass ${ }^{13)}$. Bhatti et al. ${ }^{14)}$ and Jang et al. ${ }^{15)}$ obtained acicular ferrite in the weld metals containing titanium as low as $0.005 \mathrm{wt} \%$ without intended alloying of titanium and boron from welding materials. These facts suggest that preferable acicular ferrite can be nucleated even in the existence of very small amount of titanium. The objective of the experiment-Part two is to confirm this hypothesis.

\subsection{Experimental Procedure}

Two different steels of the $20 \mathrm{~mm}$ thickness were used in the present experiment; one (steel STC in Table 7) is laboratory-melted without titanium and the other (steel STD in Table 7) is a commercial steel bearing titanium. Table 7 shows their chemical compositions. Both plates were submerged-arc welded with the same welding materials which are solid electrode wires of a $\mathrm{Si}-\mathrm{Mn}$ system with $4 \mathrm{~mm}$ diameter and an agg. lomerated fluoride-basic type of SAW flux. Table 8 shows the chemical compositions of the wire and flux. They contain no titanium source. Table 9 shows the condition of SAW with two electrodes in tandem by one-pass welding under $\mathrm{V}$ groove preparation. The weld metals were subjected to chemical analyses, microscopic observa-
Table 7 Chemical compositions of the steels (wt\%).

\begin{tabular}{|l|cccccccc|}
\hline Mark & C & Si & Mn & P & S & Ti & Cu & Ni \\
\hline STC & 0.08 & 0.17 & 1.63 & 0.002 & 0.004 & $<0.002$ & 0.27 & 0.50 \\
\hline STD & 0.10 & 0.20 & 1.49 & 0.005 & 0.003 & 0.015 & 0.26 & 0.37 \\
\hline
\end{tabular}

Table 8 Chemical compositions of the wire and flux (wt\%).

\begin{tabular}{|c|c|c|c|c|c|c|}
\hline \multirow{3}{*}{$\begin{array}{l}\text { Wolding material } \\
\begin{array}{c}\text { Chemical } \\
\text { compositions } \\
\text { (wt\%) }\end{array}\end{array}$} & \multicolumn{4}{|c|}{ Flux } & \multicolumn{2}{|c|}{ Electrodo } \\
\hline & $\mathrm{sio}_{2}$ & $\mathrm{Al}_{2} \mathrm{O}_{3}+\mathrm{MnO}$ & $\Sigma \mathrm{CaO}+\mathrm{MgO}$ & $\mathrm{CaF}_{2}$ & si & $\mathbf{M n}$ \\
\hline & 15 & 20 & 40 & 25 & 0.110 .02 & 2.02 \\
\hline Size & & & - & & $4.0(\mathrm{~mm}$ & $n \nmid)$ \\
\hline
\end{tabular}

Table 9 Welding condition.

\begin{tabular}{|c|c|c|c|c|c|}
\hline Electrode & $\begin{array}{c}\text { Current } \\
\text { (A) }\end{array}$ & $\begin{array}{c}\text { Voltage } \\
\text { (V) }\end{array}$ & $\begin{array}{l}\text { Welding speed } \\
(\mathrm{mm} / \mathrm{s})\end{array}$ & $\begin{array}{l}\text { Heat Input } \\
(\mathrm{k} J / \mathrm{mm})\end{array}$ & $\begin{array}{l}\text { Groove shape } \\
\text { (Unit in mm) }\end{array}$ \\
\hline Leading & 950 & 36 & \multirow{2}{*}{8.3} & \multirow{2}{*}{7.5} & \\
\hline Trailling & 700 & 40 & & & \\
\hline
\end{tabular}

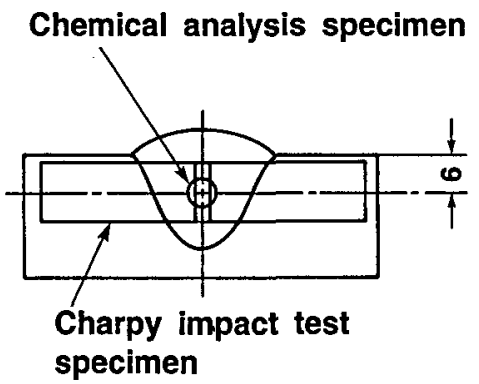

(Unit in $\mathbf{m m}$ )

Fig. 7 Removal location of test specimens.

Table 10 Chemical compositions of the weld metals (wt\%, *: ppm)

\begin{tabular}{|c|c|c|c|c|c|c|c|c|c|}
\hline Mark & c & Si & $M n$ & $\mathbf{P}$ & $\mathbf{s}$ & $\mathbf{N i}$ & $\mathrm{Cu}$ & $\pi$ & $\mathbf{B}^{:} \mid \mathbf{N}^{*} \mathbf{O}^{*}$ \\
\hline WMC & 0.086 & 0.13 & 1.63 & 0.012 & 0.005 & 0.32 & 0.20 & $<0.002$ & $<1$ \\
\hline WMD & 0.096 & 0.16 & 1.57 & 0.014 & 0.004 & 0.23 & 0.18 & 0.005 & \\
\hline
\end{tabular}

tions and Charpy v-notch impact tests. Fig. 7 shows the removal location of test specimens from a weld. The present experiment also included X-ray diffractions on extracted residues of weld metals. The procedure for oxide extraction was shown in the experiment-Part one.

\subsection{Experimental Results}

Table 10 shows the chemical compositions of the SA weld metals. The weld metal WMC was provided by welding of the steel STC. Therefore, WMC contained no titanium, as shown in Table 10 , where $0.002 \mathrm{wt} \%$ means the chemical analysis limit of titanium. The weld metal WMD was 
provided from the steel STD, and thus contained $0.005 \mathrm{wt} \%$ titanium by dilution of the plate.

Microscopic observation showed the same results of the experiment-Part one; the weld

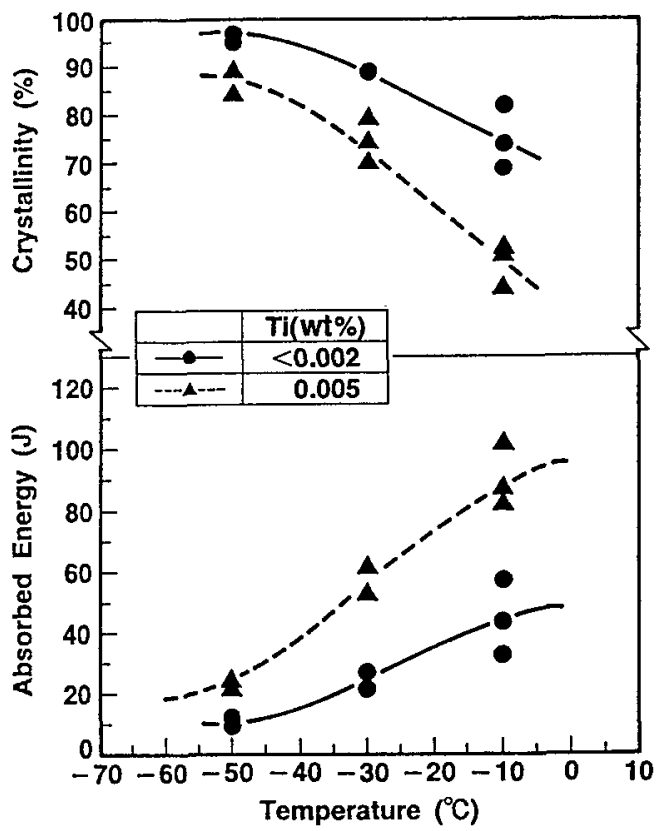

Fig. 8 Charpy impact test results of WMC $(<$ $0.002 \mathrm{wt} \% \mathrm{Ti})$ and WMD $(0.005 \mathrm{wt} \% \mathrm{Ti})$.
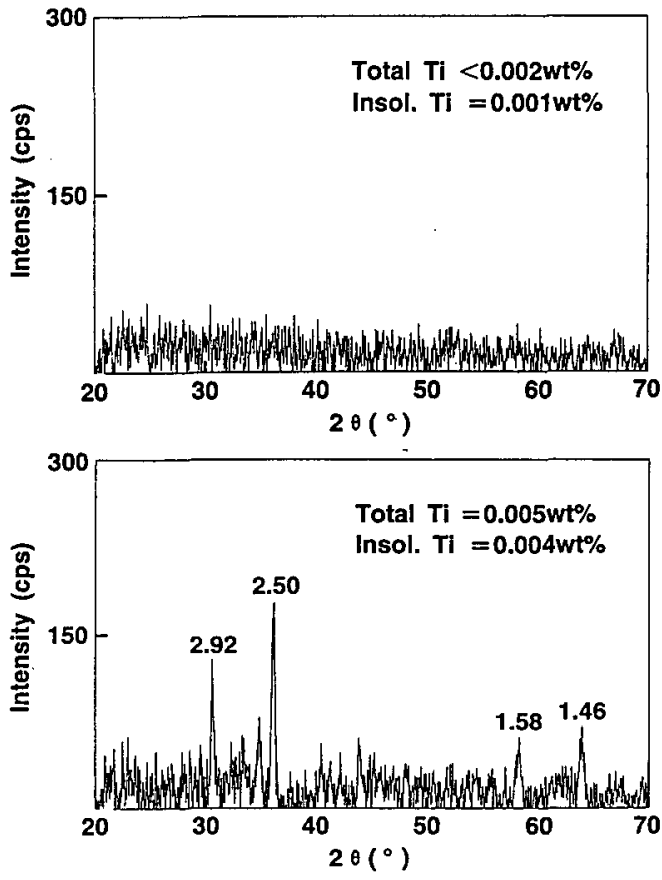

Fig. 9 X-ray diffractions on the extracted residues of weld metals WMC and WMD. metal WMC is of a FS type and WMD is of an AF type just as shown in Fig. 2. Fig. 8 shows the Charpy impact test results of the weld metals WMC and WMD. The toughness was higher in the weld WMD than in the weld WMC mainly because of the difference in their microstructures.

Fig. 9 shows $\mathrm{X}$-ray diffractions on the extract. ed residues from the weld metals WMC and WMD. The weld metal WMC showed no distinct intensity peaks in the $\mathrm{X}$-ray diffraction while some peaks were recognized in the weld metal WMD. The contents of acidinsoluble titanium were 0.001 and $0.004 \mathrm{wt} \%$ in the weld metals WMC and WMD, respectively. The acidinsoluble titanium is estimated to come mostly from titanium oxides in the weld metals because any titanium nitrides could not be identified by TEM observations. In Fig. 9, d-values (lattice plane spacing) were denoted. These d-values also coincided well with those of $\mathrm{MnAl}_{2} \mathrm{O}_{4}$ in the PDFS data as well as those of the oxides in the Ti type weld metals shown in Fig. 3(b). Therefore, the oxides in the weld WMD is of a spinel type $\mathrm{MnAl}_{2} \mathrm{O}_{4}$. The present experiment proved that a titanium content in oxides as low as $0.004 \mathrm{wt} \%$ is sufficient in creating the crystallized oxides in weld metals.

\section{Discussion}

It was found in the present experiment that intragranular acicular ferrite is obtained even in the weld metal containing $0.005 \mathrm{wt} \%$ titanium as well as in the Ti type weld metal containing 0.011 wt\% titanium. Their toughness was higher than that of the $\mathrm{Si}-\mathrm{Mn}$ type weld metal, but lower than that of the Ti-B bearing welds reported in other papers ${ }^{4,16}$. Coexisting grain boundary ferrite deteriorates the toughness in the Ti-type welds without boron. No acicular ferrite was present in the Si-Mn type weld metal and the WMC weld metal with titanium less than $0.002 \mathrm{wt} \%$. Another important finding is that oxides in the weld metals with acicular ferrite (WMA and STD) have a spinel type of crystal structure, and oxides in the weld metals having no acicular ferrite (WMB and STC) were amorphous. These facts imply that oxides having a spinel structure are effective as a nucleant of intragranular acicular ferrite. Titanium was not detected in oxides in the Si-Mn type weld metal (WMB) as shown in Fig. 5, while being observed in the oxides in the Ti type weld metal (WMC) as shown in Fig. 4. Other chemical compositions of oxides were almost the same between the $\mathrm{Ti}$ type and the $\mathrm{Si}-$ Mn type weld metals. Considering the fact that 
titanium is used as a catalyzer for the crystallization of glass $^{13)}$, these experimental results indicate that titanium in an oxide facilitates the change of oxide structure from an amorphous type to a spinel crystal type.

The oxides crystallized by titanium was identified as $\mathrm{MnAl}_{2} \mathrm{O}_{4}$. However an EDS analysis of Fig. 4(c) revealed that manganese, aluminum and titanium always coexist in crystallized oxides. Therefore, this oxide should be described as $(\mathrm{Mn}$ and/or $\mathrm{Ti}) \cdot(\mathrm{Al} \text { and/or } \mathrm{Ti})_{2} \cdot \mathrm{O}_{4}$. In the present experiments, $\mathrm{TiO}$ was not observed. However, Mori et al. concluded from their X-ray diffraction analysis that oxides in the weld metal of a $\mathrm{Ti}-\mathrm{B}$ system is $\mathrm{TiO}^{4}$. This difference in an oxide structure may be attributed to the fact that a titanium content in their weld metal was more than $0.020 \mathrm{wt} \%$, i.e., much higher than the level in the present experiments.

It is noteworthy that not a high content of titanium but a very low cotent of titanium $(0.005$ to $0.011 \mathrm{wt} \%$ ) can sufficiently crystallizes oxides. capable of nucleating intragranular ferrite. However, when the aluminum content is rather high compared with the oxygen content in weld metals $\left(\mathrm{Al} / \mathrm{O} \geq 1.125\left(=\mathrm{Al} / \mathrm{O}\right.\right.$ in $\left.\mathrm{Al}_{2} \mathrm{O}_{3}\right)$ ), most of oxygen combines with aluminum, and the oxides will not contain titanium. Thus, they will be amorphous. Therefore, an appropriate balance of aluminum and oxygen contents in weld metal is needed to acquire titanium containing oxides and beneficial acicular ferrite structure ${ }^{14)}$. Dowling et al. and Mills et al. reported the existence of a spinel type $\mathrm{MnAl}_{2} \mathrm{O}_{4}$ in titanium bearing weld metals. Dowling et al. ${ }^{5)}$ identified the spinel $\mathrm{Al}_{2} \mathrm{O}_{3} \cdot \mathrm{MnO}$ in addition to titanium bearing phases. Also, they stated "the low melting phases may have an amorphous structure" from their experiment on weld metals with titanium ranging from nil (less than $0.005 \mathrm{wt} \%$ ) to $0.029 \mathrm{wt} \%$. Nevertheless, they could not experimentally identify amorphous structures in oxides. Mills et al. ${ }^{67}$ also reported that a spinel oxide of $\mathrm{Al}_{2} \mathrm{O}_{3} \cdot \mathrm{MnO}$ exists in a titanium bearing weld metal and that a glassy phase with manganese silicate is dominate in the weld metal with a high oxygen content. It should be noted that all the weld metals in their research included titanium more than $0.007 \mathrm{wt} \%$ and acicular ferrite as microstructure. Therefore, the experimental results by Dawling et al. and Mills et al. are not sufficient enough to fully understand the effect of the titanium addition to a $\mathrm{Si}-\mathrm{Mn}$ weld metal on a change in an oxide structure.

The macroscopic analysis (X-ray diffraction) and microscopic observation (AEM) in the present experiments, along with their researches, have clarified the difference in a oxide structure between $\mathrm{Ti}$ type weld metals and $\mathrm{Si}-\mathrm{Mn}$ type weld metals. Furthermore, it was confirmed in the present experiments that oxides in the $\mathrm{Si}-\mathrm{Mn}$ type weld metal containing no titanium has a amorphous structure and that the addition of a very low amount $(0.005 \mathrm{wt} \%)$ of titanium facilitates the crystallization of an amorphous oxide.

Many models on the formation of the acicular ferrite have been proposed*; they are classified as an epitaxial growth model ${ }^{4,6,20)}$, a thermal expansion coefficient model ${ }^{13,14)}$, an oxide inclusion size mode ${ }^{15)}$ and a sympathetic transformation model ${ }^{21}$. There was no clear difference in oxide size between the Ti type and the $\mathrm{Si}-\mathrm{Mn}$ type weld metal in the present experiment and the oxide inclusion size model can not be applied to the transformation with titanium. Since the misfit value of lattice between the substrate of $\mathrm{TiO}$ or $\mathrm{TiN}$ and the ferrite matrix is small, the epitaxial growth model by effective nucleation sites was proposed. The misfit value of a spinel type oxide, $\mathrm{Al}_{2} \mathrm{O}_{3} \cdot \mathrm{MnO}$ is $1.8 \%$ between the oxide and ferrite. This misfit is less than that of $\mathrm{TiO}$ and TiN. Hence, the epitaxial growth can be expected at the interface of the spinel oxide.

On the other hand, there is not such relationship between amorphous oxides and ferrite in the $\mathrm{Si}^{-}$ $\mathrm{Mn}$ type weld metals.

It was reported that manganese sulfide is effective for the intragranular ferrite transformation as a nucleation site in a steel heat affected $z_{0}{ }^{17,18)}$. In the present experiment, deposits of manganese sulfide on the oxide surface were recognized in the $\mathrm{Ti}$ type weld metal as well as the $\mathrm{Si}-\mathrm{Mn}$ type weld metal. However, the manganese sulfide played no important role on the intragranular ferrite nucleation in the weld metals with titanium between nil and $0.011 \mathrm{wt} \%$ in the present research. This result also agrees with the conclusion by Devillers et al. ${ }^{19)}$.

\section{Conclusions}

(1) The oxides in weld metals containing tita-

\footnotetext{
* Other mechanisms on acicular ferrite transformations also have been proposed. They are summarized by Horii Y. in "Recent Development on Controlling the Microstructure and Toughness of Low Alloy Weldments", Proceedings of Nishiyama Memorial Technical Lecture (written in Japanese), The Iron and Steel Institute of Japan, p. 46-p. 48, No. 128, February 15, 1989.
} 
nium have a crystallized $\mathrm{Al}_{2} \mathrm{O}_{3} \cdot \mathrm{MnO}$ structure with an angularly rugged surface. Those in the silicon-manganese deoxidized weld metal have the amorphous structure with a smooth spherical shape.

(2) A very low content $(0.005 \mathrm{wt} \%)$ of titanium in a weld metal is sufficient to crystallize oxides, if titanium is included in the oxide by controlling an appropriate balance of aluminum and oxygen contents in the weld metal.

(3) Misfit value of the spinel oxide to ferrite is less than that of TiO, and therefore, nucleation of the acicular ferrite at spinel oxides is thought to be explained by the epitaxial growth model.

(4) Manganese sulfide depositing on oxides plays no important role on the intragranula ferrite nucleation in the weld metal.

\section{Acknowledgements}

The authors would like to thank Mr. Masakuni Wakabayashi, Nippon Steel Corporation, for his corporation in this study.

\section{References}

1) Y. Horii, Progress in welds for modern steels including TMCP, J. of HPI of Japan, 31-3 (1993) 16.

2) R.A.Farrar et al., Acicular Ferrite in CarbonManganese Weld Metals ; an overview, J of Material Science, 22 (1987) 3812.

3) T. Kato et al., Large Heat Input Submerged-Arc Welding of $50 \mathrm{kgf} / \mathrm{mm}^{2}$ Cryogenic Steel, IIW Doc. A $-979-82,1982$.

4) N. Mori et al., "Mechanism of Notch Toughness Improvement in Weld Metals Containing Ti and B", Journal of the Japan Welding Society, 50-2 (1981) 174.

5) J.M. Dowling et al., "Inclusion Phase and the Nucleation of Acicular Ferrite in Submerged Arc Welds in High Strength Low Alloy Steels", METALLURGICAL TRANSACTIONS A, 17A-9 (1986) 1611.

6) A.R. Mills et al., Nature of Inclusions in Steel Weld Metal and their Influence on Formation of Acicular Ferrite, Materials Science and Technology, 3 (1987) 1051.

7) I. Watanabe et al., "Effects of Titanium, Boron and Oxygen on Notch Toughness - Study on Notch Toughness of Weld Metal in Large Current MIG Arc
Welding (Report 1) -", Journal of the Japan Welding Society, 49-11 (1980) 772.

8) T. Yamaguchi et al., Proceedings of Symposium "Welding Metallurgy of TMCP Steels" (in Japanese), May, 1985, Tokyo, Japan.

9) Y. Itoh et al., "Study on Charpy Impact Properties of Welds (Report 2) -Relationship between Charpy Impact Properties and Control of Micro Structures of Weld Metals-", Journal of the Japan Welding Society, 44-10 (1975) 815.

10) D.J. Abson, et al., "Guide to the light microscope examination of ferritic steel weld metals", IIW Doc. IX-1533-88, 1988.

11) S. Ohkita et. al., "The effect of oxide inclusion on the microstructure of $\mathrm{Ti}-\mathrm{B}$ containing weld metal", Australian Welding J. 29-3 (1984) 29.

12) Powder Diffraction File, J.C.P.D.S. International Center for Diffraction Date, 1987.

13) L. Devillers et al., "The effects of low level concentrations of some elements on toughness of submergedarc welded C-Mn steel welds", Proceedings of International Conference on Trends in Welding Research, p. 609-p. 613, 1986, Gatlinburg, Tennessee, USA.

14) A.R. Bhatti et al., "Analysis of Inclusions in Submerged Arc Welds in Microalloyed Steels", Welding J., 63-7 (1984) 224s.

15) J. Jang et al., "Inclusion Effects on Submerged Arc Weld Microstructure", Journal of Materials Science, 22 (1987) 689.

16) Y. Horii et a1., "Study on Toughness of Large HeatInput Weld Metal for Low Temperature Service TMCP Steel", Seitetsu Kenkyu, No. 327 (1987) 3.

17) M. Okumura et al., "Effect of Cleanliness of Steel on its weldability", Journal of the Japan Welding Society, 6-1 (1988) 144.

18) K. Yamamoto et al., "ASTM symposium, Residuals and Unspecified Elements in Steel", November, 1987.

19) L. Devillers et al., "The Effects of Residual Impurity and Microalloying Elements on Weldability and Weld Properties, Paper 1; 1984 Abington, T.W.I.

20) G. Thewlis, The Influence of Pipe Plate and Consumable Chemistry on the Composition, Microstructure and Toughness of Submerged Arc, Seam Weld Metal, IIW Doc. IIA-736-88, 1988.

21) R.A. Ricks et al,, The Nature of Acicular Ferrite in HSLA Steel Weld Metals, 17-3 (1982) 732-740.

22) H. Homma et al., "Improvement of HAZ Toughness of HSLA Steels by Finely Dispersed Ti-Oxide, Welding J., 66 (1987) 301s. 